I N F ORM A T I R

Jurnal Informatika, Manajemen dan Komputer, Vol. 9, No. 2, Desember 2017

eISSN : 2580-3042

pISSN : 1979-0694

\title{
IMPLEMENTASI PROXY SERVER DI SMP NEGERI 1 DUMAI MENGGUNAKAN SISTEM OPERASI CLEAROS
}

\author{
Budi Irawan ${ }^{1}$, Hayatullah Khumaini ${ }^{2}$ \\ ${ }^{1,2}$ Sekolah Tinggi Manajemen Informatika Dan Komputer (STMIK) Dumai \\ Jl. Karya Utama Bukit Batrem,Kota Dumai - Riau \\ e-mail : budiirawan_21@yahoo.com
}

\begin{abstract}
ABSTRAK
Telah dilakukan penelitian pada SMPN 1 Dumai, dimana permasalahan selama ini penggunaan internet pada SMPN 1 Dumai masih mengguakan sharing hub, jadi setiap client yang online langsung terhubung ke internet tanpa adanya perantara yang mengamankan lalulintas data yang seringkali memboroskan pemakain bandwidth. Maka dalam penelitian ini akan dibuat sebuah proxy server yang bertindak sebagai caching content dan filter yang dapat menghemat pemakain bandwidth, membersihkan pop up yang ada pada halaman web dan menyaring halaman yang memiliki unsur pornografi sehingga semua client yang online akan nyaman dan tidak memerlukan waktu yang lama untuk mengakses website yang pernah diakses karena sudah tersimpan pada server local yang ada di proxy. Tujuan pembuatan proxy server pada SMPN 1 Dumai dengan sistem operasi ClearOS 6.8 adalah menciptakan sebuah server yang dapat menyimpan beberapa file dan juga website yang telah di filter agar dapat diakses oleh semua client dalam lingkungan SMPN 1 Dumai dengan aman. Dengan adanya proxy server diharapkan akan memebantu dan memudahkan client dalam mengakses website yang sehat dan baik.
\end{abstract}

Kata kunci : Linux ClearOS, Proxy Server, caching, filter

\section{PENDAHULUAN}

Penggunaan jaringan internet semakin lama semakin meningkat. Kebutuhan akan layanan ini seringkali menjadi hal yang diperlukan alam sebuah instansi atau lembaga. Internet merupakan jaringan komputer internasional yang menghubungkan suatu perangkat dengan perangkat lain dalam skala dunia untuk saling berkomunikasi dan bertukar data. SMP Negeri 1 Dumai yang beralamat di Jl.Pattimura, no.26 memiliki 56 guru yang erdiri dari 51 orang pegawai negeri dan 5 orang guru bantu, 20 orang staf tatausaha, 27 kelas dengan 768 siswa ini adalah salah satu pengguna fasilitas internet. Namun kebanyakan pengguna internet di wilayah SMP Negeri 1 Dumai mengunjungi beberapa situs yang sama secara berulang-ulang, ketika ada pengguna melakukan aktifitas download dan membuka situs vidio online yang berlebihan dapat menyebabkan pemborosan pemakaian bandwidth sehingga traffic internet menjadi tinggi, Selain itu website yang diakses pengguna sering terdapat jendela pop up yang dapat mempengaruhi traffic yang sedang berjalan. Pop up yang terjadi dapat mengganggu kinerja komputer yang membuatnya semakin lama dalam melakukan processing data. Pop up juga menampilkan konten yang kurang pantas dilihat oleh peserta didik dan guru dalam melaksanakan proses pembelajaran. Pop up adalah jendela yang biasanya muncul tiba-tiba ketika mengunjungi halaman web. Biasanya berisi iklan yang tidak diperlukan dan harus disingkirkan agar tidak mengganggu proses menjelajah web.

Berdasarkan permasalahan di atas, maka manajemen jaringan sangat diperlukan untuk manajemen bandwidth pada setiap pengguna dan meminimalisirkan penyalahgunaan internet yang dilakukan oleh pengguna. Salah satu alat bantu jaringan internet yaitu proxy server yang berfungsi sebagai mengontrol dan menyimpan chaching file tertentu dari halaman web yang pernah diakses. Jika pengguna mengakses website yang sama maka file tadi diambil dari cach proxy sehingga mempercepat akses ke website yang dituju dan mengurangi kepadatan traffic internet. Proxy server juga memiliki content filter yang berfungsi untuk menyaring atau memblokir akses dari suatu situs tertentu maka pengguna dapat dicegah agar tidak dapat membuka situs yang dilarang.

Untuk mengimplementasikan proxy server maka dibutuhkan sistem operasi yang berguna untuk menjalankan program aplikasi pada 


\section{N F O R M A I K}

Jurnal Informatika, Manajemen dan Komputer, Vol. 9, No. 2, Desember 2017

eISSN : 2580-3042

pISSN : 1979-0694

komputer. Salah satu sistem operasi yaitu sistem operasi ClearOS. Sistem operasi ClearOS adalah Linux yang dikostumasi khusus untuk keperluan server.Dengan berbagai fitus yang powerfull dan setting simple, ClearOS menjadi alternatif pilihan, baik untuk pemula yang tidak mengerti Linux sama sekali maupun untuk profesional yang memerlukan kemampuan terbaik dari OS linux server. Berbasis Linux Red Hat Enterprise 5, menjadikan ClearOS memiliki source base yang kuat dan stabil untuk dijalankan sebagai server di warnet, game online, kantor-kantor, dan perusahaan.

Berdasarkan latar belakang diatas, maka dapat di identifikasikan beberapa masalah yaitu sebagai berikut :

1. Adanya kesulitan melakukan manajemen bandwith internet.

2. Adanya pengguna yang membuka situs video online dan download sehingga menyebabkan jaringan down.

3. Adanya pop up iklan yang mengandung unsur pornografi.

Adapun tujuan dari penelitian ini sebagai berikut :

1. Membahas tentang fungsi caching dan content filter pada ClearOS.

2. Penelitian ini di lakukan di SMP Negeri 1 Dumai.

3. Perancangan sistem yang dibahas adalah instalasi dan konfigurasi Proxy server menggunakan Sistem Operasi ClearOS 6.8

\section{METODOLOGI PENELITIAN}

Untuk membantu dalam penyusunan metodologi penelitian ini, maka perlu adanya susunan kerangka penelitian yang jelas tahapantahapannya. Kerangka kerja ini merupakan langkah-langkah yang akan dilakukan dalam penyelesaian masalah. Adapun kerangka Kerja penelitian sebagai berikut :

1. Mengidentifikasi Masalah

Permasalahan yang terjadi pada SMPN 1 Dumai masih menggunakan sharing hub, jadi setiap client yang online langsung terhubung ke internet tanpa adanya perantara yang mengamankan lalulintas data yang seringkali memboroskan pemakain bandwidth. Maka dalam penelitian ini akan dibuat sebuah proxy server yang bertindak sebagai caching content dan filter yang dapat menghemat pemakain bandwidth, membersihkan pop up yang ada pada halaman web dan menyaring halaman yang memiliki unsur pornografi sehingga semua client yang online akan nyaman dan tidak memerlukan waktu yang lama untuk mengakses website yang pernah

diakses karena sudah tersimpan pada server local yang ada di proxy.

2. Menganalisa Masalah

Penganalisaan terhadap masalah yang telah diidentifikasikan perlu dilakukan, apakah perlu dilakukan pembuatan proxy server pada SMPN 1 Dumai dengan sistem operasi ClearOS 6.8

3. Menentukan Tujuan

Tujuan utama dalam penelitian ini menciptakan sebuah server yang dapat menyimpan beberapa file dan juga website yang telah di filter agar dapat diakses oleh semua client dalam lingkungan SMPN 1 Dumai dengan aman.

4. Mengumpulkan Data

Pengumpulan data survey ke SMPN 1 Dumai, buku atau literature yang berhubungan dengan pembuatan proxy server dengan system operasi clearOS 6.8.

5. Melakukan Perancangan

Melakukan perancangan jaringan proxy server dengan system clearOS6.8.

6. Melakukan Pengujian

Melakukan pengujian apakah server yang telah di buat dapat menyimpan beberapa file dan juga website yang telah di filter agar dapat diakses oleh semua client dalam lingkungan SMPN 1 Dumai dengan aman.

7. Kesimpulan

Setelah dilakukan pengujian, langkah berikutnya adalah penentuan/pengambilan keputusan berdasarkan hasil yang telah dilakukan sebelumnya, sehingga akan muncul hasil program yang prioritas atau yang tidak prioritas.

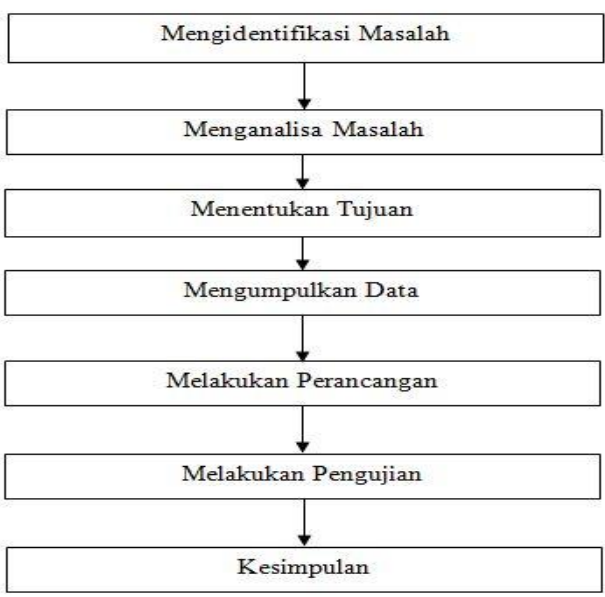

Gambar 1. Kerangka Penelitian 
I N F ORM A T I R

Jurnal Informatika, Manajemen dan Komputer, Vol. 9, No. 2, Desember 2017

eISSN : 2580-3042

pISSN : 1979-0694

\section{HASIL DAN PEMBAHASAN \\ a. Gambar Jaringan Komputer}

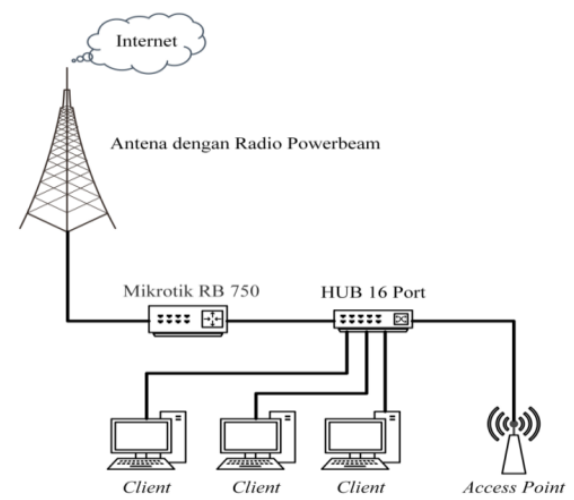

Gambar 2. Jaringan komputer

Pada gambar diatas, jaringan internet dialirkan menggunakan antena radio dari ISP Fajar Link ke router, kemudian diteruskan ke $h u b$, dari hub langsung dialirkan ke client. Apabila client ingin browsing maka client langsung terhubung ke internet untuk mendapatkan content yang diinginkan.

\section{b. Permasalahan Sistem Jaringan}

Berdasarkan gambar 1. Jaringan Komputer, permasalahan yang sering muncul pada umumnya bandwidth yang digunakan oleh client tidak terbagi sama rata, adanya pengguna yang membuka situs video online dan download sehingga menyebabkan jaringan down, Adanya pop up iklan yang mengandung unsure pornografi.

\section{c. Alternative Pemecahan Masalah}

Berdasarkan permasalahan sistem jaringan diatas, solusi yang dapat dijadikan sebagai alternatif pemecahan masalah adalah dengan menggunakan proxy server. Dengan menggunakan proxy server maka client tidak berhubungan langsung dengan jaringan internet, sehingga permintaan client ditangani dahulu oleh proxy server.

Proxy server akan membantu untuk "mempercepat" browsing dari komputer client. Dengan menggunakan sistem cache, maka beberapa objek di internet yang sering di akses oleh client akan di simpan secara otomatis di server, apabila ada client lain yang memerlukan, akan diambilkan dari server lokal, sedangkan content yang tidak tersedia maka proxy sever akan mencari di internet kemudian di simpan kembali proxy server

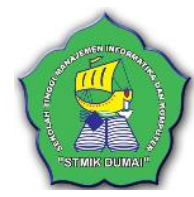

d. Perancangan Proxy Pada Jaringan Lokal Perancangan dapat ditempatkan pada berbagai model topologi jaringan, untuk merancang sebuah topologi yang tepat pada jaringan ini terdapat beberapa hal yang perlu diperhatikan antara lain, lokasi, jarak, dan biaya.

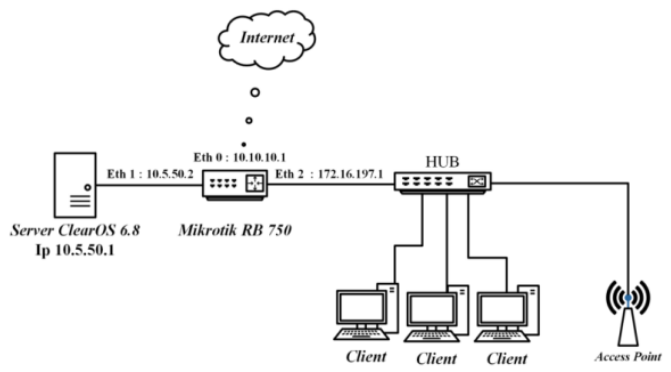

Gambar 3. Rancangan Instaasi Proxy

e. Instalasi ClearOS

Persiapan Instalasi

1. CD Instalasi ClearOS 6.8

2. CD/DVD Internal / External

\section{Proses Installasi}

1. Boot awal

2. Pada saat ini tekan Enter untuk melanjutkan proses Intalasi

3. Pengecekan Pada Media Installasi

4. Pilih skip untuk instalasi ClearOS, kemudian tekan Enter

5. Halaman awal Installasi ClearOs

6. Pilih next untuk melanjutkan kehalaman berikutnya

7. Pemilihan Bahasa untuk Installasi

8. Pilih bahasa yang akan digunakan pada Installasi Clear OS, Kemudian tekan Next.

9. Pemilihan Bahasa Installasi Pada Keyboard

10. Pilih bahasa yang akan digunakan pada keyboard untuk instalasi ClearOS, Kemudian tekan next

11. Pemilihan Perangkat yangakan diinstall

12. disini digunakan basic storage device kemudian next

13. Memberikan nama Host Name

14. Biarkan saja nama dari sistem kemudian next.

15. Pilih Zona Waktu

16. Pilih Asia/Jakarta kemudian next .

17. Password root ClearOS

18. Root Password: 123456

Confirm : 123456

kemudian next

19. Pemilihan Partisi Untuk Installasi

20. Pilih Use All Space kemudian pilih next

21. Konfirmasi Pengisntallan Pada Disk

22. Pilih Write changes to disk kemudian next

23. Proses Installasi ClearOs 
INFORM T IKA

Jurnal Informatika, Manajemen dan Komputer, Vol. 9, No. 2, Desember 2017

eISSN : 2580-3042

pISSN : 1979-0694

\section{Instalasi selesai}

Untuk login ke web config masukkan user name dan password yang telah di buat sebelumnya,

User name : root

Password : 123456

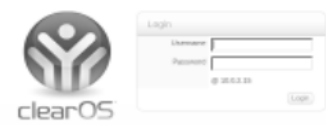

Gambar 4. Tampilan login web config ClearOS

Settingan awal ClearOS memberikan IP secara DHCP, kemudian rubah menjadi static.

Gambar 5. Tampilan Settingan Ethernet ClearOS

Masukkan settingan yang ingin di rancang Ip Address : : 10.5.50.1

Netmask : :255.255.255.0

Gateway : 10.5.50.2

Pilih update

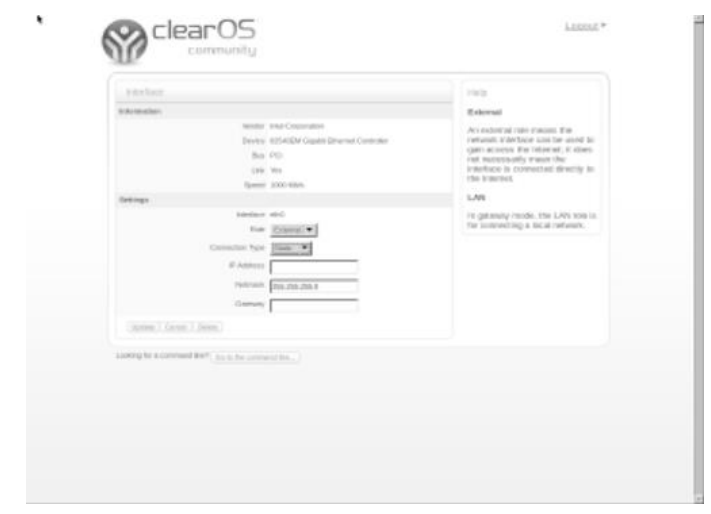

Gambar 6. Tampilan Ethernet 0 ClearOS

f. Konfigurasi ClearOS

Pengaturan filter website

a. Pada squid.conf hilangkan tanda \# di Black Listed

Domains

\# Black Listed Domains

\#acl blacklistdoms dstdomain -i

'/etc/squid/blacklist.txt'

\#deny_info

http://trustpositif.kominfo.g

o.id/ blacklistdoms

\#http_access deny blacklistdoms

\#store_miss deny blacklistdoms

\#send_hit deny blacklistdoms

menjadi :

\# Black Listed Domains

acl blacklistdoms dstdomain $-i$

'/etc/squid/blacklist.txt'

deny_info

http://trustpositif.kominfo.g

o.id/ blacklistdoms

http_access deny blacklistdoms

store_miss deny blacklistdoms

send_hit deny blacklistdoms

b. Pada /etc/squid/blacklist.txt masukkan nama website yang akan di blokir, seperti:

doubleclick.net

porn.com

fapmommy.com

\section{Pengaturan filter iklan / pop up}

a. Pada squid.conf hilangkan tanda \# di Advertising Blocker, Advertising atau iklan produk dari suatu barang yang berada di halaman suatu website walaupun tidak $100 \%$ iklan yang terblokir dari website yang di akses

karena banyak iklan yang muncul dari situs yang berbeda karena ada pembaharuan dari penyedia layanan iklan.

\# Advertising Blocker

\#acl yoyoads dstdom_regex $-i$

'/etc/squid/yoyo-adservers.txt'

\#deny_info

http://adzapper.sourceforge.net/

zaps/ad-clear.gif yoyoads

\#http_access deny yoyoads

menjadi :

\# Advertising Blocker

acl yoyoads dstdom_regex $-i$

'/etc/squid/yoyo-adservers.txt'

deny_info

http://adzapper.sourceforge.net/

zaps/ad-clear. gif yoyoads

http_access deny yoyoads 
INFORM T IKA

Jurnal Informatika, Manajemen dan Komputer, Vol. 9, No. 2, Desember 2017

eISSN : 2580-3042

pISSN : 1979-0694

b. Pada /etc/squid/ yoyoadservers.txt masukkan daftar adservers yang akan di diblokir,

seperti :

(^^). $101 \mathrm{com} \backslash . \operatorname{com} \$$

(^)..)101orderl.com\$

(^)..)123found`.com\$

(^). 180 hits\.de\$

(^)..)180searchassistantl.com\$

(^ᄉ). $1 \times 1$ rankl.com\$

\section{Pengujian Proxy}

a. Pengujian Streaming video online tanpa proxy

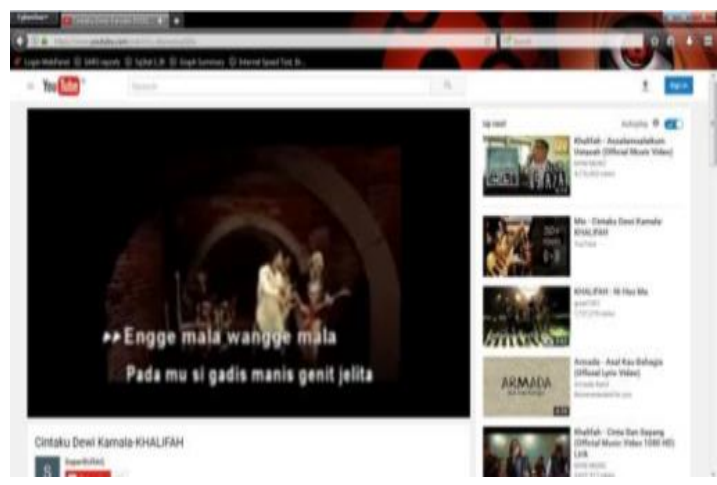

Gambar 7 Situs Youtube.com diakses tanpa proxy.

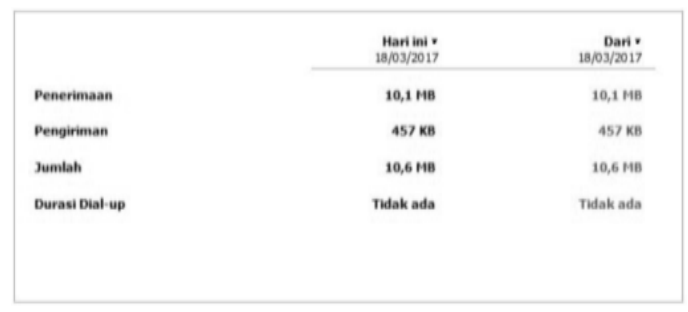

Gambar 8 Bandwidth yang digunakan tanpa proxy

Keterangan :

Situs vidio online yang diakses tanpa menggunakan proxy membutuhkan bandwidth 10,6 MB untuk menyelesaikan satukali pemutaran vidio online.

b. Pengujian Streaming video online menggunakan proxy untuk pertama kali.

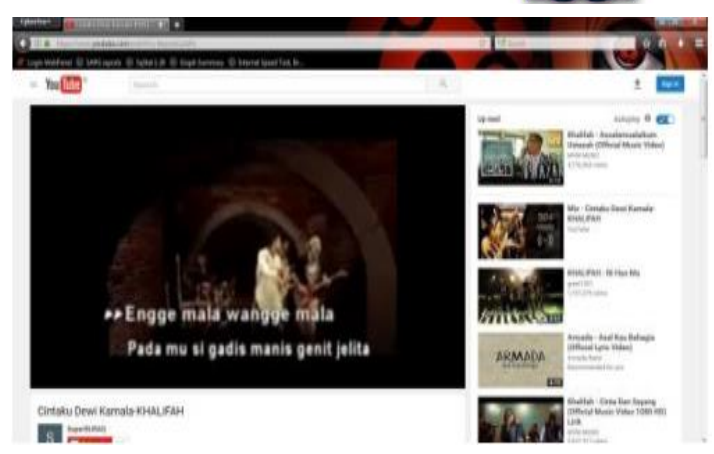

Gambar 9 Situs Youtube.com diakses dengan proxy untuk pertama kali

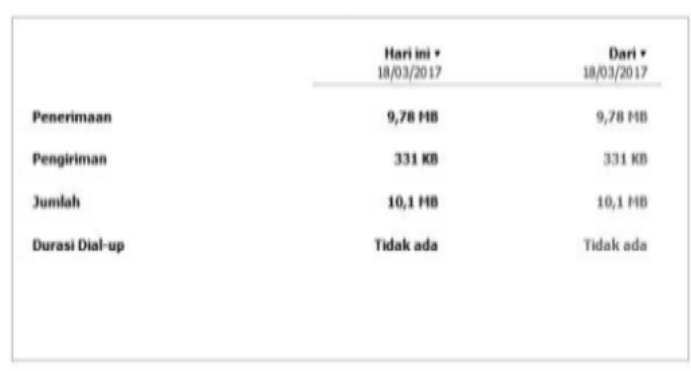

Gambar 10 Bandwidth yang digunakan proxy untuk pertama kali

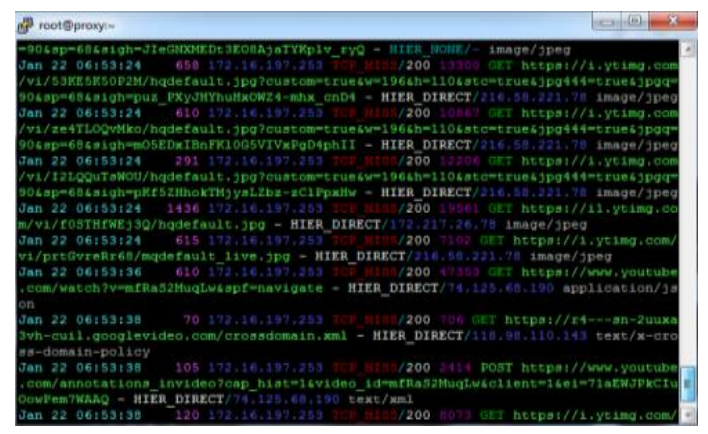

Gambar 11 Log Youtube.com untuk pertama kali mengakses video

Keterangan :

Situs vidio online yang diakses menggunakan proxy pertama kali membutuhkan bandwidth 10,1 MB untuk menyelesaikan satu kali pemutaran video online,pada saat ini proxy memulai untuk mencache object. 
I N F ORM A T I R

Jurnal Informatika, Manajemen dan Komputer, Vol. 9, No. 2, Desember 2017

eISSN : 2580-3042

pISSN : 1979-0694

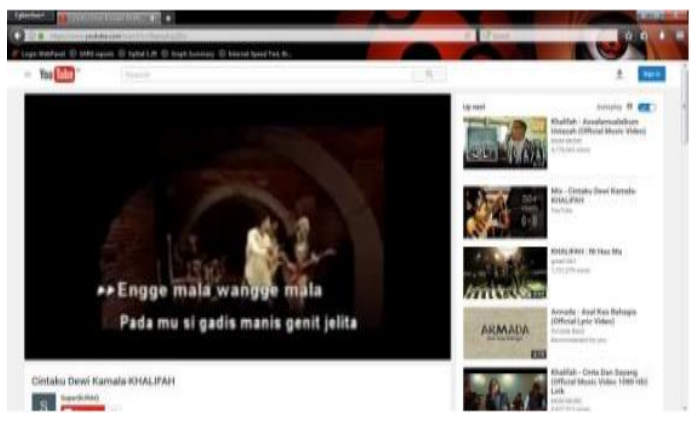

Gambar 12 Situs Youtube.com diakses dengan proxy

\begin{tabular}{|lrr|}
\hline & $\begin{array}{c}\text { Hari ini r } \\
18 / 03 / 2017\end{array}$ & $\begin{array}{r}\text { Dari } \\
18 / 03 / 2017\end{array}$ \\
\cline { 2 - 3 } Penerimaan & $7,98 \mathrm{MB}$ & $7,98 \mathrm{MB}$ \\
Pengiriman & $207 \mathrm{~KB}$ & $207 \mathrm{~KB}$ \\
Jumlah & $\mathbf{8 , 1 8} \mathrm{MB}$ & $8,18 \mathrm{MB}$ \\
Durasi Dial-up & Tidak ada & Tidak ada \\
& & \\
& & \\
\hline
\end{tabular}

Gambar 13 Bandwidth yang digunakan proxy untuk mengakses video

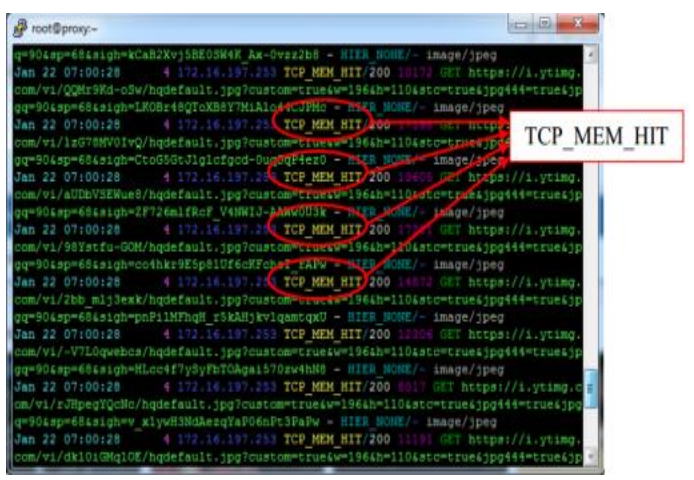

Gambar 14 Log Youtube.com setelah diakses

Keterangan :

Lingkaran merah pada gambar 13 Log Youtube.com setelah diakses merupakan hasil log squid pada situs youtube untuk setelah di akses oleh pengguna dan terlihat $T C P \_M E M \_H I T$ yang berwarna kuning, pada saat ini data yang diminta oleh pengguna berasal dari cache pada server local squid yang sedang berjalan. Situs vidio online yang diakses menggunakan proxy membutuhkan bandwidth 8,18 MB untuk menyelesaikan satu kali pemutaran vidio online.

c. Grafik Pengujian Bandwidth

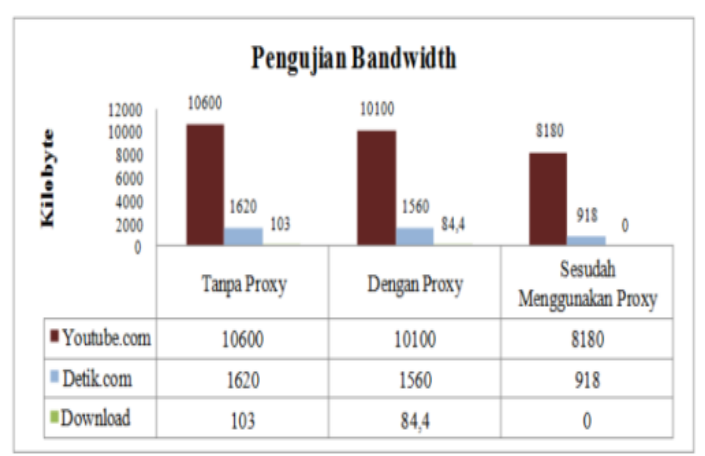

Gambar 15 Grafik Pengujian Bandwidth

Keterangan :

Dapat dihat perbandingan pemakain bandwidth dalam jaringan, untuk mengakses content tanpa proxy, content tersebut diambil dari server aslinya dan menggunakan bandwidth langsung dari modem.

Untuk mengakses content menggunakan Proxy dapat menghemat penggunaan bandwidth karena proxy akan caching objek yang diakses oleh

pengguna kemudian disimpan ke server local dan memberikan kembali kepada pengguna yang mengakses situs yang sama dalam jaringan, sehingga dapat menghemat penggunaan bandwidth dan menampilkan content yang sama lebih

cepat.

\section{KESIMPULAN}

Kesimpulan yang dapat ditarik pada Penelitian ini adalah sebagai berikut :

a. Proxy server yang telah dirancang dapat memanajemen bandwidth dan sebagai filter dengan menggunakan ClearOS pada jaringan internet SMP Negeri 1 Dumai.

b. Proxy Server sebagai cache content dapat menyimpan object dari jaringan internet yang diakses oleh pengguna sehingga pengguna lain mengakses content yang sama seperti yang pernah diakses akan lebih cepat dan tidak membutuhkan bandwidth yang besar.

c. Bandwidth yang dapat di hemat menggunakan proxy server hampir $40 \%$ dari proses awal mengakses suatu content tergantung dengan jumlah pengunjungn yang mengakses content tersebut.

d. Dapat digunakan sebagai filter yang disesuaikan dengan kebutuhan penggunaan internet. 
I N F ORM A T I A

Jurnal Informatika, Manajemen dan Komputer, Vol. 9, No. 2, Desember 2017

eISSN : 2580-3042

pISSN : 1979-0694

e. Memblokir pop up dan iklan tidak dapat berjalan dengan sempurna karena pop up dan iklan yang ada pada halaman web memiliki alamat yang berganti terus secara dinamic oleh produsen/sponsor yang ingin mendapatkan keuntungan dengan adanya pop up dan iklan tersebut.

f. Lebih hemat biaya karena dibuat dengan spesifikasi minimum server dan kebutuhan pengguna.

\section{REFERENSI}

Catur Andi Kurnianto, et al.(2013). Jurnal Jarkom : Manajemen Bandwidth Menggunakan Delay Pools di Squid Proxy (Studi Kasus : SMAN 1 Sragen). ISSN: 2338-6313.57-63.

Dores Hardito, et al (2012) . Jurnal DASI : Analisa dan Perancangan Pembatasan Akses WEB Browser di Kantor Camat Langgam Kabupaten Pelalawan Provinsi Riau. ISSN : 1411-3201. 7-14

Eka Iswandy.(2015). Jurnal TEKNOIF : Sitem Penunjang Keputusan Untuk Menentukan Penerimaan Dana Satuan Sosial Anak Nagari dan Penyalurannya Bagi Mahasiswa dan Pelajar Kurang Mampu di Kenagarian Barung-Barung Balantai Timur. ISSN: 2338-2724. 7079

Hasnul Arifin.(2011). Kitab Suci Jaringan Internet Komputer dan Koneksi Internet. MediaKom. Jakarta

I Putu, A.E .(2014). Handbook Jaringan Komputer. Informatika. Bandung Iwan Sofana .(2012). Cisco CCNA dan Jaringan Komputer Informatika Bandung

Opik Taupik K,et al.(2013). Pembuatan Aplikasi Anbiyapedia Ensiklopedia Muslim Anak Berbasis Web. ISSN: 1979$8911 . \quad 33-52$ Rendra Towidjojo (2012). Konsep \& Implentasi dengan Router Mikrotik :100\% Connected.Jasakom

(2016). Mikrotik Kungfu : Kitab 1(Edisi Revisi). Jasakom (2013). Mikrotik Kungfu : Kitab 2. Jasakom

Siswo wardoyo, et al.(2014). Jurnal Nasional Teknik Elektro: Analisis Performa File Transport Protocol Pada Perbandingan Metode Ipv4 Murni, Ipv6 Murni Dan Tunneling 6 to 4 Berbasis Router Mikrotik . ISSN: $2302-2949$. 106-117

Siti Munawaroh (2007). Jurnal Teknologi Informasi Dinamik : Penyaringan Akses Internet menggunakan Squid Linux. ISSN : 0854-9524. 56-66

Winarno Sugeng dan Theta Dinnarwaty ,P. (2014). Jaringan Komputer dengan TCP/IP. Modula. Bandung 